\title{
Um moço muito branco: estrangeiro
}

\author{
Ramiro Giroldo*
}

Resumo: O texto toma como objeto o conto "Um moço muito branco", de João Guimarães Rosa, e tem como objetivo a leitura do personagem do título como uma peculiar figura da alteridade. Embasa-se em noções formuladas por Sigmund Freud em "O estranho". A leitura do unheimlich promovida por Neuza Santos Souza no texto "O estrangeiro: nossa condição” também é levada em conta.

Palavras-chave: João Guimarães Rosa; unheimlich; alteridade.

\begin{abstract}
The paper discusses the short-story "Um moço muito branco", by João Guimarães Rosa. It intends to read the title character as a singular otherness conformation. The paper is founded on notions formulated by Sigmund Freud in "O estranho". Neusa Santos Souza's reading of the unheimlich in "O estrangeiro: nossa condição" is took into account.
\end{abstract}

Keywords: João Guimarães Rosa; unheimlich; otherness.

O texto é subdividido em quatro partes. A primeira é uma breve paráfrase do conto "Um moço muito branco", permeada por comentários analíticos que assinalam pontos de interesse à presente discussão. A segunda se propõe a expor o conceito de unheimlich conforme apresentado por Sigmund Freud. O intuito é embasar a terceira parte, que busca uma articulação entre o texto "O estrangeiro: nossa condição" e o conto aqui em pauta. Por fim, as considerações finais da quarta parte pretendem assinalar o vínculo entre "Um moço muito branco" e a crítica à filosofia do sujeito promovida pela psicanálise.

\section{Um moço muito branco}

"Um moço muito branco" narra a visita de um forasteiro a uma comunidade interiorana de Minas Gerais. Uma semana antes de sua primeira aparição, um evento cataclísmico tomara lugar:

um fenômeno luminoso se projetou no espaço, seguido de estrondos, e a terra se abalou, num terremoto que sacudiu os altos, quebrou e entulhou casas, remexeu vales, matou gente sem conta. (...) Mesmo a distância do astroso arredor, a muita criatura e criação pareceu, soterradas ou afogadas. Outros vagavam ao deus-dar, nem sabendo mais, no avesso, os caminhos de outrora (ROSA, 1985, p. 90).

Avistado, o "moço muito branco" se aparenta, no trajar e na desorientação, aos sobreviventes que vagavam sem destino. Contudo, dada a peculiaridade de sua aparência,

\footnotetext{
* Doutorando em Literatura Brasileira na Faculdade de Filosofia, Letras e Ciências Humanas da USP. Orientando do Prof. Dr. Jaime Ginzburg.
} 
estranha aos da pequena cidade, é sugerido que ele não seja, na verdade, um sobrevivente do desastre - a relação entre sua vinda e o cataclismo seria algo distinta.

A aparência, a proverbial "primeira impressão", é denunciada como enganosa, não apenas porque uma criatura benfazeja como o moço tenha surgido de um grande desastre, mas principalmente porque seu tão evidente estrangeirismo acabe paradoxalmente se revelando um parentesco.

O trecho que narra a primeira aparição do moço, bastante significativo, instaura a instância que percorrerá todo o conto, de certa forma antecipando o desenvolvimento posterior do enredo:

O que foi quando subitamente, e era moço de distintas formas, mas em lástima de condições, sem o restante de trapos com que se compor, pelo que enrolado em pano, espécie de manta de cobrir cavalos, achada não se supõe onde; e, assim em acanho, foi ele avistado, de muito manhã, aparecendo e se escondendo por detrás do cercado das vacas. Tão branco; mas não branquicelo, senão que de um branco leve, semidourado de luz: figurando ter por dentro da pele uma segunda claridade. Sobremodo assemelhava a esses estrangeiros que a gente não depara nem nunca viu; fazia para si outra raça (Idem, p. 90-91).

É sintomático que o moço se "assemelhe" a estrangeiros que nunca foram vistos. A formulação é paradoxal, já que a priori seria impossível reconhecer aquilo que não se conhece, conhecer o que ainda é desconhecido. Esse jogo entre conhecido e desconhecido, familiar e estrangeiro, se apresenta como o motivo central do conto, ficcionalmente desenvolvido em diversos momentos.

Desamparado, "perdida a completa memória de si, sua pessoa, além do uso da fala" (Idem, p. 90-91), o moço recebe hospedagem do rico Hilário Cordeiro. O povoado cria apreço por ele e muitos são os que comparecem à propriedade de Cordeiro para visitá-lo. A exceção é Duarte Dias, pai da bela Viviana, que "se sabia ser homem de gênio forte, além de maligno e injusto, sobre prepotências: naquele coração não caía nunca sequer uma chuvinha” (Idem, p. 92).

Conforme posteriormente é dado a saber, Dias invejava Cordeiro. Sua ausência é devida não ao descaso para com o "moço muito branco", mas ao contrário: quer ser ele a acolhê-lo em sua propriedade. Prepotente, quer a dádiva para si, e deseja desde o princípio resguardá-la dos outros como se sua propriedade fosse.

A impressão que do moço tem o padre Bayão, na missa, é a de uma espécie superior de homem, desvinculado do mundano e, talvez, mais próximo do divino: "Comparados com ele, nós todos, comuns, temos os semblantes duros e o aspecto de má fadiga constante" (Idem, p. 92). 
À saída da igreja, o moço entrega a um pedinte cego uma semente que, plantada meses depois, dá origem a um pé de flores que nunca se tinha visto igual, "mais rara e inesperada" (Idem, p. 93). Deve-se assinalar que o presente do moço não pôde ser desfrutado por aquele que o recebeu; cego, este não seria capaz contemplar a exótica beleza das flores.

O conto sugere, nesse episódio, que as dádivas oferecidas pelo celestial moço não podem ser plenamente desfrutadas justamente porque o homem comum não possui a faculdade necessária para perceber-lhes a verdadeira natureza. Pode apenas, tateando, vislumbrar a nova percepção que o moço tanto oferece quanto demanda, nunca apreendê-la em sua plenitude.

Duarte Dias, fazendo uso de um falso pretexto, pede que o moço fique sob sua guarda. Hilário Cordeiro não aceita renunciar à "propriedade" e mantém o moço sob sua guarda. Vê tudo dar certo em sua vida, por obra da presença do moço: "eis que tudo lhe passou a dar sorte, quer na saúde e paz, em sua casa, seja no assaz prosperar dos negócios, cabedais e haveres" (Idem, p. 93). Pode-se notar que o ingênuo moço é tratado como uma coisa a possuir tanto por Dias quanto por Cordeiro, cada um se atribuindo o direito legítimo de mantê-lo próximo.

Após tocar o seio de Viviana, o moço é pressionado por Dias a se casar com ela: "Afirmava que o moço era homem, e um, e ainda mancebo, e lhe infamara a filha, devendolhe de a tomar por consorte e arcar com o estado de casado" (Idem, p. 94). A defesa da honra de Viviana se revela mais um pretexto, do qual Dias é logo dissuadido, para ter o moço sob seu teto.

Tocada pelo moço, Viviana é alterada: "Ela, que, a partir dessa hora, despertou em si um enfim de alegria, para todo o restante de sua vida, donde um dom" (Idem, p. 94). Duarte Dias, posteriormente, também acaba se modificando por obra do moço, transformado em "homem sucinto, virtuoso e bondoso, suspendentemente, consoante o asseverar sobremaravilhado dos coevos" (Idem, p. 95).

De forma tão repentina quanto chegara, o moço parte. Ajudado pelo negro Kakende, certa noite acende nove fogueiras, talvez sinais para que seus pares, nos céus, pudessem localizá-lo. Então, “com a primeira luz do sol, o moço se fora, tidas asas” (Idem, p. 95). O povoado sente sua ausência com tristeza e se revela, com exceção de Viviana, incapaz de preservar o que o moço despertara: "Ele cintilava, ausente. Pois. E mais nada." (ROSA, 1985, p. 95).

\section{Unheimlich}


Se o unheimlich de Sigmund Freud é o estranho ambivalentemente familiar, o outro que se mostra o mesmo, uma leitura de "Um moço muito branco" pode bastante se beneficiar do conceito.

Embora seja tão pronta e decisivamente classificado como estrangeiro, as características reveladas pelo personagem-título despertam na pequena comunidade uma perspectiva que não é apenas diferente, mas que fora esquecida. É importante destacar, nesse ponto, que a evocação de um passado dificilmente apreendido em sua plenitude, mas ainda assim presente e constituinte, caracteriza o "retorno do mesmo" apresentado em "O estranho".

É pertinente, antes de partir para a articulação teórica, apresentar as ambiguidades e as ambivalências de que se reveste o conceito e que etimologicamente são observáveis no próprio termo unheimlich - daí a opção em mantê-lo, aqui, no original.

Sigmund Freud toma como ponto de partida uma discussão a respeito da etimologia da palavra unheimlich, para depois formular conceitualmente o efeito. O procedimento adotado põe em evidência a precisão do termo na descrição de um efeito literário específico e acaba por tornar imprecisas as tentativas de tradução. A palavra alemã, afinal, apresenta nuances ausentes em termos análogos de línguas como o latim, o grego, o árabe, o hebreu, o inglês, o francês, o espanhol, o italiano e o português, conforme proposto por Freud em "O estranho".

Em um primeiro sentido, unheimlich seria apenas o oposto plano e direto de heimlich:

\begin{abstract}
A palavra alemã "unheimlich" é obviamente o oposto de "heimlich" ["doméstica"], "heimisch" ["nativo"] - o oposto do que é familiar; e somos tentados a concluir que aquilo que é "estranho" é assustador precisamente porque não é conhecido e familiar. Naturalmente, contudo, nem tudo o que é novo e não familiar é assustador; a relação não pode ser invertida. Só podemos dizer que aquilo que é novo pode tornar-se facilmente assustador e estranho; algumas novidades são assustadoras, mas de modo algum todas elas. Algo tem de ser acrescentado ao que é novo e não familiar, para torná-lo estranho (FREUD, 1996, p. 239).
\end{abstract}

Prosseguindo com a especulação etimológica, por meio de comentários a excertos de dicionários, Freud assinala um sentido peculiar que a palavra heimlich pode expressar, crucial para sua formulação do conceito: "escondido", "oculto da vista alheia". Assim, heimlich se equipara ao seu oposto, unheimlich. É possível, com base no dado, definir porque nem tudo o que é novo e não familiar é unheimlich. Segundo Freud, "heimlich é uma palavra cujo significado se desenvolve na direção da ambivalência, até que finalmente coincide com o seu oposto, unheimlich. Unheimlich é, de um modo ou de outro, uma subespécie de heimlich" (Idem, p. 244).

Assim, enquanto palavras como "estranho" ou "sinistro" são unilaterais e desprovidas tanto de ambiguidades quanto de ambivalências, unheimlich, na percepção exposta por Freud, 
expressa uma simultaneidade: é, a um só tempo, o assustador e o outrora familiar ou conhecido.

Trata-se do retorno do reprimido; o efeito se constitui quando um texto evoca algo "secretamente familiar [heimlich-heimisch], que foi submetido à repressão e depois voltou" (Idem, P. 262). Em outras palavras, o unheimlich traria à tona desejos reprimidos e modos superados de pensamento, estes últimos vinculados a uma concepção animista e supersticiosa do mundo.

Um conto tomado como modelar para o estudo do efeito é "O homem de areia", de E. T. A. Hoffmann. O tema principal do conto, responsável pela expressão do unheimlich é, para Freud, justamente o Homem de Areia, figura que arrancaria os olhos das crianças que não vão para a cama à noite. Freud assinala a etimologia de Copéllius/Coppola, nome do Homem de Areia: coppo=cavidade orbital. À luz da relação substitutiva entre o olho e órgão masculino, "que se verifica nos sonhos, mitos e fantasias" (Idem, 249), o temor de ferir ou perder os olhos é, na concepção freudiana, vinculado ao "complexo de castração". Como a substituição do medo de ser castrado pela ansiedade em relação aos olhos tem suas raízes na infância, o conto é unheimlich - promove, afinal, o retorno do reprimido, do esquecido.

\section{Um moço muito branco: estrangeiro}

O unheimlich remete a uma inquietação terrorífica, marca ausente no efêmero que "Um moço muito branco" configura. Assim, a articulação aqui empreendida entre o efeito de que trata o texto de Freud e o conto de Rosa não pretende afirmar que este alcance um efeito afim ao de obras como "O homem de areia". As proposições de Freud, contudo, podem se mostrar produtivas à discussão de "Um moço muito branco" se adequadamente mediadas e ponderadas.

A reflexão sobre o unheimlich promovida por Neuza Santos Souza no texto "O estrangeiro: nossa condição" pode servir a tal mediação, sendo de auxílio a uma compreensão das reações provocadas pelo "moço muito branco" na comunidade interiorana que o recebe.

Observemos, primeiramente, em que termos a autora apresenta como psicanaliticamente deve ser vista a questão da alteridade:

O estrangeiro, diz o senso comum, é o outro. Outro que se afirma em muitos sentidos: outro país, outro modo de estar na vida, de fruir, de gozar. O estrangeiro é o outro do familiar, o estranho; o outro do conhecido, o desconhecido; o outro do próximo, o distante, o que não faz parte, o que é de outra parte.

Para a psicanálise, o estrangeiro é o eu. $\mathrm{O}$ eu, não tomado como o quer o senso comum unitário, coerente, idêntico a si mesmo - , mas o eu pensado em sua condição paradoxal - 
dividido, discordante, diferente de si mesmo - tal como, de uma vez por todas, o poeta nos ensinou: "Eu é um outro" (SOUZA, 1998, p. 155).

Não por acaso Souza contrapõe a noção da psicanálise à do senso comum. A incompreensão e a não aceitação do outro resulta no preconceito que se crê disseminado e contra o qual o texto "O estrangeiro: nossa condição" oferece uma possível saída. Segundo a autora, o efêmero, se acolhido, permitiria que o estranho se conjugasse

não com inquietude, desalento, dor e medo, paixões tristes, mas (...) com a alegria do novo, com a afirmação do múltiplo, afirmação trágica do plural, do diferente. Só assim o estranho viria a se definir como afirmação alegre da diferença, verdadeiro antídoto contra toda forma de racismo. O racismo é essa peste, olhar odioso que afeta o Outro, visada de ódio e intolerância àquilo que funda Sua diferença. Ódio e intolerância ao Outro, o racismo é essa maneira funesta de pensar e agir, fruto de uma vontade totalitária em seu duplo afã de extirpar do Outro o seu modo de gozo e, ao mesmo tempo, de lhe impor o nosso.

Contra o racismo de todas as cores, de todos os sexos, de todas as crenças, de todas as línguas, de todas as culturas, de todos os países, contra esse horror, que no valha o estrangeiro do exterior e do interior de nós mesmos (Idem, p. 163).

É possível dizer que a comunidade apresentada em "Um moço muito branco" acolhe prazerosamente o outro e nele se enxerga. A inquietação que acompanharia a presença do estrangeiro, que teria como consequência o medo e o racismo (nos termos de Souza) não aparece. O contato com o outro, porém, se mantém problemático: a comunidade aceita e admira o celestial moço, mas tristemente se revela incapaz de acolher a transitoriedade do encontro e preservar aquilo que fora, em brechas, relembrado. Falhando em aceitar a efemeridade, se mostram incapazes de manter aquilo que o moço neles revelara.

O segmento em que o moço entrega uma estranha semente ao cego é bastante ilustrativo. O belo pé de flor que ele é impossibilitado de contemplar dura pouco e não produz mais sementes. As flores não podem ser plena e racionalmente apreendidas, como o moço. Quando murcham, deixam o vazio onde poderiam ter deixado um olhar passível de suprir a cegueira que o cego toma como intrínseca. Para tanto seria necessário acolher, aceitar, a efemeridade das flores.

Dias morre de tristeza, enquanto "Hilário Cordeiro, e outros, diziam experimentar uma saudade e meia-morte, só de imaginarem nele" (ROSA, 1985, p. 95). A exceção é Viviana, que "conservou sua alegria" (Idem, p. 95, grifo nosso). Por que seria a filha de Duarte Dias a única a preservar o que a visita do moço despertara?

Uma provável resposta pode ser encontrada no viço de Viviana. Embora dona de uma "vagarosa tristeza" (Idem, p. 94), a bela moça, em sua juventude e mesmo inexperiência, talvez não estivesse ainda permeada pela perspectiva utilitária dos que a cercavam. Afinal, o bem que ela preserva é a alegria que tem valor por si própria, um sentimento de agradável 
cultivo, enquanto seu pai, por exemplo, muda de postura porque "pensou que ia virar riquíssimo" (Idem, p. 95).

Na perspectiva aqui apresentada a modificação promovida pelo moço não se teria dado propriamente pela inserção de novas maneiras de encarar o Outro, mas pelo despertar do que estaria adormecido. Lembremos, nesse ponto, que o unheimlich cuja articulação com "Um moço muito branco" aqui se procurou efetuar é caracterizado pelo retorno de formas de articular a realidade que se viram superadas em prol de uma visada outra.

Esse retorno a um estado inicial do qual não se lembra mais pode ser articulado de forma proveitosa a um traço da produção literária de João Guimarães Rosa como um todo: a desconstrução (reconstrução?) da língua, sempre movida pela procura de uma língua primeva, paradoxalmente pré-verbal e capaz de falar do que escapa ao pensamento mecanicista e utilitário.

\section{4 "Um moço muito branco" e o descentramento do eu}

Joel Birman, no primeiro capítulo de Estilo e Modernidade em Psicanálise, intitulado "O Sujeito no Discurso Freudiano", apresenta noções de interesse à discussão aqui empreendida. A citação que segue, longa, será justificada adiante:

Para Freud, a psicanálise representaria a terceira grande "ferida narcísica" da humanidade, que teria sido precedida historicamente pela revolução copernicana na cosmologia e pela revolução darwiniana na biologia. A proposição do descentramento do sujeito é uma"ferida narcísica" para o eu e para o indivíduo, na medida em que retira destes o suposto domínio sobre as suas ações. Porém, esse novo descentramento não é de natureza diferente daqueles que retiraram o homem do centro das ordens do cosmo e da vida, que representaram "feridas narcísicas" para a humanidade.

Com efeito, se com Copérnico a Terra foi deslocada do centro do cosmo e inserida na posição secundária de ser um dos diversos planetas que giram ao redor do Sol, com Darwin o homem perdeu o seu lugar privilegiado na ordem da natureza e se inscreveu nesta como uma espécie derivada de outras espécies na evolução biológica. Assim, se o homem acreditava um lugar destacado no cosmo e no campo do olhar divino, com a teoria heliocêntrica de Copérnico essa pretensão teria caído por terra, delineando-se então um universo infinito, no interior do qual se inseria o homem amedrontado. Da mesma forma, o homem podia se representar como um ser superior aos demais e ao olhar divino, ao supor a sua superioridade no mundo da natureza. Porém, a leitura darwiniana da evolução das espécies teria remetido definitivamente o homem para as suas dimensões animais, inserindo-o na escala evolutiva das espécies (BIRMAN, 1993, p. 19).

Por fim, a terceira é constituída por Freud como crítica à filosofia do sujeito e sua idéia de um homem senhor de si. Dessa forma, a maior resistência à psicanálise, de acordo com Freud, viria de princípios fundamentados na pretensão do eu e da consciência terem domínio completo do aparelho psíquico do indivíduo.

Nas palavras de Birman, 
a psicanálise teria retirado ancoragem da pretensão humana, o último reduto da superioridade do homem, ao enunciar que a consciência não é soberana no psiquismo do indivíduo e que o eu não é autônomo no funcionamento psíquico. Vale dizer, o ser do psíquico se desloca da consciência e do eu para os registros do inconsciente e da pulsão, que passam a regular materialmente o ser do psiquismo (Idem, p. 20).

"Um moço muito branco" é um texto que carrega a percepção de que o sujeito não é senhor de si próprio e, assim, expõe a "ferida narcísica" provocada pela psicanálise. O personagem-título provoca reações e desperta sentimentos cujo manejo escapa às capacidades dos homens que com ele travam contato, incapazes de apreender produtivamente as características e sentimentos perdidos trazidos à tona pelo contato com o moço.

O conto, nesse sentido, tematiza literariamente uma questão central em nossos tempos: o homem pode se revelar incapaz de compreender algo que ajuda a constituí-lo.

\section{Referências}

BIRMAN, Joel. O sujeito no discurso freudiano: a crítica da representação e o critério da diferença. In: Estilo e modernidade em psicanálise. São Paulo: Editora 34, 1993.

FREUD, Sigmund. O estranho. In: Edição Standard das Obras Psicológicas Completas de Sigmund Freud, Volume XVII. Traduzido do alemão e do inglês sob a direção geral de Jayme Salomão. Rio de Janeiro: Imago, 1996.

HOFFMANN, E. T. A. O homem de areia. Tradução de Bárbara Theoto Lambert. In: TAVARES, Braulio (Org.) Freud e o estranho: contos fantásticos do inconsciente. Rio de Janeiro: Casa da Palavra, 2007.

ROSA, João Guimarães. Um moço muito branco. In: Primeiras Estórias. 14. ed. Rio de Janeiro: Nova Fronteira, 1985.

SOUZA, Neusa Santos. O estrangeiro: nossa condição. In: KOLTAI, Caterina (Org.). O estrangeiro. São Paulo: Escuta, 1998. 